\title{
Danger on the Way to School: Exposure to Violent Crime, Public Transportation, and Absenteeism
}

\author{
Julia Burdick-Will, Marc L. Stein, Jeffrey Grigg
}

Johns Hopkins University

\begin{abstract}
In this study, we propose and test a mechanism for the effect of neighborhood of residence on school outcomes: absenteeism that results from exposure to danger on the way to school. We first determine the most efficient route to school using public transportation for 4,200 first-time freshmen in Baltimore City public high schools. Then, we link the specific streets along the most efficient route to incident-level crime data from the Baltimore Police Department. We find that students whose estimated routes require walking along streets with higher violent-crime rates have higher rates of absenteeism throughout the year. We also show that absenteeism is not associated with exposure to dangerous streets while riding on public transit and exposure to property crime. These conclusions hold with and without adjustments for student demographic characteristics, prior school attendance, violent crime around homes and schools, and unobserved differences related to school preference and neighborhood selection.
\end{abstract}

Keywords: neighborhoods; education; violence; transportation

Citation: Burdick-Will, Julia, Mark L. Stein, and Jeffrey Grigg. 2019. "Danger on the Way to School: Exposure to Violent Crime, Public Transportation, and Absenteeism." Sociological Science 6: 118-142.

Received: November 8, 2018

Accepted: December 31, 2018

Published: February 13, 2019

Editor(s): Jesper Sørensen, Kim Weeden

DOI: $10.15195 / \mathrm{v} 6 . \mathrm{a} 5$

Copyright: (C) 2019 The Author(s). This open-access article has been published under a Creative Commons Attribution License, which allows unrestricted use, distribution and reproduction, in any form, as long as the original author and source have been credited. (C) (i)
THE relationship between neighborhood violence and academic outcomes is 1 now well established in the sociological literature on neighborhood effects. Students who are exposed to areas with high rates of violent crime, regardless of whether they are involved in those crimes, have lower test scores and graduation rates than those who are from safer neighborhoods (Burdick-Will 2016; Harding 2009; Schwartz et al. 2016; Sharkey 2010). The mechanisms that generated these effects are often conjectural and have not been evaluated with empirical evidence. For example, Sampson, Sharkey, and Raudenbush (2008) suggest that linguistic isolation due to social withdrawal and maternal depression might explain their estimated relationship between concentrated disadvantage and children's verbal ability. Similarly, Harding (2010) describes the collective socialization of youth in violent neighborhoods as potentially limiting prosocial behavior and leading to unrealistic education aspirations, but no direct link to learning or other school outcomes is made. Sharkey et al. (2012) explain the relationship between local homicides and low test scores a few days later with symptoms of cognitive stress and limited attention span. Although these cognitive mechanisms do seem to be related to local violence exposure, the effects are relatively small and short lived and, therefore, unlikely to explain much of the relationship between neighborhood violence and academic outcomes.

In this study, we propose and test a new mechanism for the effect of neighborhood of residence on school outcomes that is grounded in concrete student behavior: absenteeism due to a dangerous commute to school. In much of the early work on neighborhood disadvantage, it was assumed that youth in poor and dangerous neighborhoods were socially and geographically isolated from the 
rest of the city and that students go to school in their own neighborhood with the same classmates they see on the street after school (i.e., Jencks and Mayer 1990; Kozol 1991; Sánchez-Jankowski 2008; Wilson 1987; Wodtke, Harding, and Elwert 2011). Given the expansion of choice programs in cities across the country (Grady and Bielick 2010), however, this is an assumption that is no longer empirically justified. Students, especially those from violent and disadvantaged neighborhoods, travel long distances to a range of schools on a daily basis (Shedd 2015). In fact, students from violent neighborhoods are more likely to attend a larger number of distinct high schools than those from safer neighborhoods (Burdick-Will 2017, 2018). This scattering across schools means getting to school is no easy task for many students. At the same time, districts across the country are cutting back on traditional "yellow-bus" chartered transportation systems due to cost and instead relying on public transportation systems to get kids to school (Urban Institute 2017; Vincent et al. 2014). Together, this means that just showing up to school every day can involve long and difficult journeys through potentially dangerous streets early in the morning (Einhorn 2016; McKone 2015).

The current literature on neighborhood disadvantage and violence has yet to catch up to the new reality of urban schooling. Getting to school safely is often discussed in passing but is rarely addressed as a potential causal mechanism linking exposure to neighborhood violence and learning loss or school disengagement. In contrast, we argue that in response to the stressors experienced during commuting, youth likely employ the same strategy that adult workers use to mitigate strain: They alter their commutes in ways that make getting to school longer or more complicated, or they avoiding the problem altogether by being absent (AmponsahTawiah, Annor, and Arthur 2016; Koslowsky, Kluger, and Reich 1995; Stutzer and Frey 2008).

To test this empirically, we use newly available forms of administrative data and spatial methods to estimate students' street-specific routes to school using public transportation and their potential exposure to high-violent-crime streets along the way. In doing so, we focus on the crime rates of specific city blocks and differentiate between the places that students must wait and walk through and the streets they pass while protected by the confines of a bus or train. Specifically, we use home- and school-address data from approximately 4,200 first-time ninth grade students enrolled in the Baltimore City schools during the 2014-2015 school year along with transportation networks and schedules provided by the Maryland Transit Administration to estimate the most efficient specific, street-by-street route to school for every student. We then link these street segments to incident-level crime reports provided by the Baltimore Police Department. We find that students whose estimated routes require walking to and waiting at transit stops along streets with higher violent-crime rates have higher rates of absenteeism throughout the year. Exposure to dangerous streets while riding on public transit and exposure to high-property-crime streets are not associated with absenteeism. The results remain after adjusting for student demographics, prior attendance, violent crime around homes and schools, and unobserved differences related to school preference and neighborhood selection. 
These findings have important implications for our understanding of how the social environment in neighborhoods shape youth behavior. First, they highlight the importance of considering school attendance patterns when evaluating neighborhood effects. Residential address no longer directly determines where students go to school in most cities. This does not mean that where students live does not impact their schooling experience. Instead, where they live is related to what it takes to show up at school every day. For some students, this means long and dangerous commutes that would be a hassle for even the most engaged and determined students. For others, it may mean walking just a few blocks down the street. Therefore, getting to school is an important source of variation both within schools and within neighborhoods. Second, these results draw attention to a new behavioral mechanism linking exposure to violence and academic outcomes: attendance. These results suggest that getting to school is not just a function of school disengagement but also of real safety concerns and constraints. Fully understanding the extent of the influence of urban crime and violence on youth behavior requires not just a psychological understanding of cognitive strain and trauma or the potential for collective socialization and local role models but also of the daily difficulties that limit students' ability to follow through on their goals of educational progress. Not showing up for school has important academic consequences, and students who must prioritize their own personal safety over attendance are at a clear disadvantage.

\section{Safety and School Attendance}

A growing body of research documents the negative relationship between exposure to violent areas and academic outcomes. For example, Harding (2009) showed that neighborhood violence can explain much of the relationship between concentrated poverty and graduation rates. Similarly, multiple studies have shown that exposure to violent neighborhoods is related to lower test scores and lower test-score growth over time (Burdick-Will 2013, 2016; Schwartz et al. 2016; Sharkey 2010). To date, much of this research has focused on crimes that take place near students' homes or schools; however, recent global positioning system (GPS) tracking data show that even among youth who live in the same neighborhood, there is wide variation in adolescent exposure to violence over the course of a week (Browning et al. 2017). This prior study of youth activity spaces discusses the extent of this variability, but it does not specifically address the commute to and from school as a potential source of variable exposure to violence. In fact, despite the focus on youth activities, there is no mention of the substantial variability in school locations or the time students take to get to and from school. Similarly, proposed mechanisms linking neighborhood violence and disadvantage focus on the cognitive stress and trauma of witnessing a crime, long-term behavioral adaptations that result from living with chronic violence, or linguistic and social isolation (Harding 2010; Sampson et al. 2008; Sharkey et al. 2012; Shonkoff et al. 2012). Research on violence at schools suggests that frequent reported crimes reduce test scores through disruptions in instruction, but this research assumes-perhaps incorrectly-that students are actually present in class (Burdick-Will 2013). 
Throughout this literature, school attendance, or lack thereof, is rarely mentioned as a direct mechanism linking neighborhood violence and educational outcomes. When it is mentioned, it is often argued that students do not go to school because they do not see the value in it or do not have positive role models (Harding 2010; Wilson 1987), not that they have actual difficulty getting there or that the threat of violence en route discourages them from even going to school.

Nevertheless, most student learning takes place in schools, and students who do not show up at school have limited opportunities to learn (Sørenson and Hallinan 1977). Chronic absenteeism has been linked to a number of negative outcomes for students, including lower achievement, course failure, and ultimately student disengagement and increased risk of dropping out of high school (Allensworth and Easton 2007; Allensworth et al. 2014; Balfanz and Byrnes 2012; Balfanz, Herzog, and Mac Iver 2007; Gottfried 2010; Mac Iver and Mac Iver 2010; Ready 2010). The problem of chronic absenteeism is especially pronounced among high-school-aged and urban youth (Balfanz and Byrnes 2012). Gottfried (2013) demonstrates a relationship between absenteeism and neighborhood contexts that operates independently from individual-level disadvantage, but little is known about exactly what it is about disadvantaged neighborhoods that increases absenteeism.

Even though the link between exposure to neighborhood violence and absenteeism has not been studied directly, themes from a wide range of qualitative urban literature suggest that physical avoidance is one of the main ways that urban residents respond to unsafe environments (i.e., Bourgois 1995; Pattillo 2008; Small 2004; Wacquant 2008). For example, Klinenberg's (2002) interviews and observations in Chicago show quite clearly that even during a deadly heat wave, fearful residents stayed inside their homes to avoid potential threats to their safety and property. Venkatesh (2000) also describes how the residents who were not directly involved in gang activity avoided public spaces in the Robert Taylor Homes. Residents do not need to be a victim of or even a witness to violent crimes in order for the crimes to be a deterrent. Information about a violent crime-especially in one's neighborhood-likely spreads via the spectacle of police presence and via social and familial networks. Awareness of these crimes may discourage students from doing things that might otherwise benefit them, such as going to school or playing outside (Harding 2010; Rosenblatt and DeLuca 2012; Sharkey 2006). Furstenberg et al. (1999) argue that parents are also highly attuned to this type of risk. When parents feel the need to protect their children, they resort to more restrictive parenting behaviors, such as keeping children home as much as possible. In other words, one key response to potential danger is to physically avoid it.

Studies of criminal activity repeatedly show that crimes, particularly violent crimes, tend to take place on specific street segments where there is an optimal combination of possible offenders, targets, and supervision (Braga, Papachristos, and Hureau 2010; Cohen and Felson 1979; St. Jean 2008). This means that even in a generally violent neighborhood, there is substantial block-to-block variability in crime rates, and students who live relatively near one another but go to school in different directions may have substantial variation in their street-level exposure to violence. Furthermore, when youth are confined to a bus or a train, they are being indirectly supervised by both the driver and the other adults on the bus or train. 
They are also not directly exposed as targets in the same way they might be if they were standing on or walking along a sidewalk. Therefore, avoiding danger on the way to school may mean avoiding school altogether, but it may also include subtle adaptations to a commute that make it safer. For example, recent journalistic reports from Baltimore and Detroit describe how students take longer, more inefficient routes to school in order to avoid particularly dangerous blocks at certain hours (Einhorn 2016; McKone 2015; see also Condliffe, Boyd, and DeLuca 2015; Harding 2010; Sharkey 2006). For example, one student in Detroit asks a neighbor for a ride to a safer bus stop each morning rather than waiting in the dark at a closer but more dangerous one (Einhorn 2016). This means that some students are not only reliant on the bus or train arriving on time but also on their neighbors' ability to give them a ride. Although they do not keep students away from school every day, these adaptations add difficulty and uncertainty to the trip, which in turn may lead to more absences from school. Given that the literature on adult commuting has established an association between increased transit difficulty and increased absenteeism from work (Kluger and Reich 1998; Koslowsky et al. 1995; Wener et al. 2003), it is likely that the same association exists among students commuting to school.

\section{Hypotheses}

Together, the literature on exposure to violence, attendance, and transit suggests that students who must travel through unsafe areas on their way to school are more likely to be absent from school. We are particularly focused on the estimated exposure to violence on the route to school rather than the general safety of the students' residential or school neighborhoods. Therefore, we examine students' most efficient commuting routes to school and hypothesize that even among students who live in the same general neighborhood, there will be variation in the safety of their commute that is related to attendance patterns. We compare these estimates to those of property-crime exposure along the same route. Nonviolent crimes (such as drug sales or theft), although involving police presence and potentially disturbing, do not pose the same threat to personal safety as violent crimes (such as assault or robbery). Therefore, we do not expect exposure to these types of crimes to have the same effect on behavior as exposure to violent crime. Specifically, we test the following hypotheses:

1. Students whose most efficient route to school requires walking or waiting on street segments with high levels of violent crime will be absent more frequently than those who are exposed to streets with lower levels of violent crime.

(a) This relationship will be stronger than the relationship between general neighborhood violence, and attendance and will remain even when comparing students who live in the same neighborhood. 
2. Exposure to streets with high levels of violent crime while confined to the inside of a bus or train will not be related to any change in the number of absences.

3. Exposure to nonviolent property crimes, either on the street or while in transit, will not be as strongly related to absenteeism.

\section{Choice and Transit in Baltimore City}

In order to assess these hypotheses, we use spatial methods to combine Baltimore City data from a variety of sources. Baltimore City is a good place to study the transition from home to school for two reasons. First, Baltimore City Public Schools ("city schools") operates on a system of universal high-school choice; there are no assigned neighborhood schools anywhere in the city, and all students must select high schools through a choice process during the winter of eighth grade. Of the 37 high schools, there are four highly selective college-preparatory schools and three selective vocational schools that admit students based on a composite score of high standardized-test scores, middle-school attendance, and grades. There is one artsfocused school that admits students on the basis of an audition performance. All other high schools admit students through a lottery scheme based on the number of applicants. This system means that there is quite a lot of variability, even within neighborhoods, in students' routes to high school (Stein et al. 2017).

Second, the city schools do not provide chartered yellow buses for students in either middle or high school. In order to help students get to school, the state of Maryland provides subsidized public transportation passes that can be used on the Baltimore City bus, metro, and light rail systems (the metro and light rail systems in Baltimore are very small, and the majority of students use buses for their commute). These passes are available to any student who lives more than 1.5 miles from their enrolled school (Baltimore City Public Schools 2018). The exact number of Baltimore students who walk or take public transportation is unknown, but a report published by the Baltimore Education Research Consortium (BERC) on a Baltimore City Public Schools student survey with a relatively low response rate (42 percent) suggests that less than one-third of high-school students ever use a car as their primary mode of transportation. The same report documents that 30 percent of students report feeling unsafe during their trip to school. Reports of safety are lowest among students who report taking public transportation to school (Stein et al. 2017).

\section{Data and Measures}

Individual-level data on student absenteeism, enrollment, transfer, and demographics are provided by the Baltimore Education Research Consortium, which maintains a longitudinal database of deidentified data from Baltimore City Public Schools (baltimore-berc.org). These records include basic demographics, such as gender, race, eligibility for free or reduced-price meals, special education and Englishlanguage-learner status, school identifiers, home address, whether the student 
attends a selective-enrollment school, and annual reported absences during the current and previous school years. Approximately 6,300 ninth graders enrolled in Baltimore's regular (i.e., not alternative or special education) public high schools during the entire 2014-2015 school year. We limit this analysis to the approximately 4,200 first-time freshmen who were stably enrolled in a single high school through the entire school year. This avoids confounding between school mobility, grade retention, exposure to violence, and attendance.

The administrative data also include records from the high-school-choice system. All students in Baltimore must register for high school through a preference- and qualification-based lottery. Students may rank up to five high schools in which they wish to enroll. As previously mentioned, selective and vocational schools require high test scores, grades, and attendance to qualify for admission. The remaining schools admit students by lottery if oversubscribed. For each student, we know the five high schools listed on their choice forms. Using these forms, we create a dummy variable for each school that takes a value of one if a student listed that school on his or her choice forms and zero if not. These choice indicators allow us to compare students who list the same schools and presumably represent similar sets of geographic and academic preferences. Because a school's desirability may influence students' willingness to be there every morning, we also include an indicator for whether students attend their first-choice school.

To estimate student commutes on public transportation, we built a Baltimore transit network using tools from ArcGIS version 10.4.1 (Morang 2016) and the General Transit Feed Specifications (GTFS) from the Maryland Transit Administration (MTA) (2017). GTFS data include the spatial network of routes as well as specific stop arrival times for every point along the network. This is the type of data that applications like Google Maps use to estimate the most efficient route at a given time. Using the GTFS data, we calculated routes from each residential address of record to the enrolled school location with an arrival time before the start of school. We then extracted schedule information (e.g., vehicle type, route identifier, and time) as well as geolocated street segments and transit stops used on this route to each school and created a number of measures of the commute, including whether the student's route involved only walking, the number of transfers needed, and the total estimated commute time.

We capture safety along the estimated route to school using officially reported incidents of violent crime. Violent-crime data come from the Baltimore Police Department (2017) "Part I Victim Based Crime Data," which includes the date, time, and precise latitude and longitude of every reported incident in the city. We used all crimes committed between the first and last days of school in the 2014-2015 academic year. We do not limit the time of day or day of the week. We do not expect that students witness all of these crimes. Nevertheless, when crime occurs, there is often an extended police presence and reporting on the location. Students may also hear about events from family or friends.

To estimate students' exposure to high-violent-crime streets during their commute, we counted the number of violent crimes that occurred on every street segment in Baltimore City. These street-segment counts were then merged to the routes generated by the ArcGIS transit network tool. Exposure to crime during 
the commute was calculated by aggregating crime counts for two portions of the student commute via public transit: walking to and from transit stops and waiting at the stops (during which the student is physically on the street) and the transit portion (during which the student is confined to the bus or train). We label these variables walking violence exposure and on-the-bus violence exposure, respectively. Figure 1 visually describes these two portions of a student's commute. For this student, getting from home (shown by the circle) to school (shown by the square) requires two buses. First, she walks from home to stop A. She then boards bus 1 and travels to stop B, where she gets off and walks to stop C. She then boards bus 2, gets off at stop D, and walks the rest of the way to school. For this student, the walking violence exposure would include all violent crimes committed along the streets that the student walked along (shown by the solid lines) and the on-the-bus violence exposure would include all violent crimes that a student passed by while on bus 1 or 2. Not all students require a transfer, and their walking exposure only includes the very beginning and end of their journey. For students who can walk to school, their exposure on the bus is zero.

We expect that students will be more sensitive to their surroundings while walking on the street or waiting for public transit than while they are sitting inside the bus or train. Our focus is on violent crime, which includes assaults, robberies, rapes, shootings, and homicides. We compare these results to those using property crimes, which include arson, burglary, larceny, and automobile theft. These crimes do not present as immediate a physical threat to victims or witnesses, and therefore, we would expect them to cause less stress during students' commute.

To compare the crime experienced on specific commuting routes to general safety in students' residential neighborhoods and around their schools, we also calculate violent-crime counts for both the neighborhoods in which the students live and the neighborhoods in which their schools are located (violent crime near home and violent crime near school, respectively). We use the 278 neighborhood boundaries that are defined by the local planning department and are well recognized boundaries throughout the city. Across neighborhoods, the median number of ninth graders is 17, and the median number of students in our analytic sample is 11. The median number of schools that students from a single neighborhood attend is 10 .

Figure 2 maps the distribution of violent crime within 100 feet of every transit stop in the city (our analysis includes all crimes committed on all street segments, but it is easier to visualize the transit-stop points than the full street grid). Baltimore's official neighborhood boundaries are included as reference points. Some stops experience quite a bit of violent crime nearby. Those marked by large, red circles experience (on average) more than one crime per month within this very small geographic area (100-foot radius). Interestingly, the high-violent-crime transit stops are relatively equally distributed across the city, including a number of unsafe stops in the whiter, wealthier, and generally low-crime areas to the north of downtown. There is also quite a bit of variation between stops even along the same route in the same part of the city. Students who wait for a bus or train just a few blocks from one another may have very different experiences with immediate exposure to violent crime. 

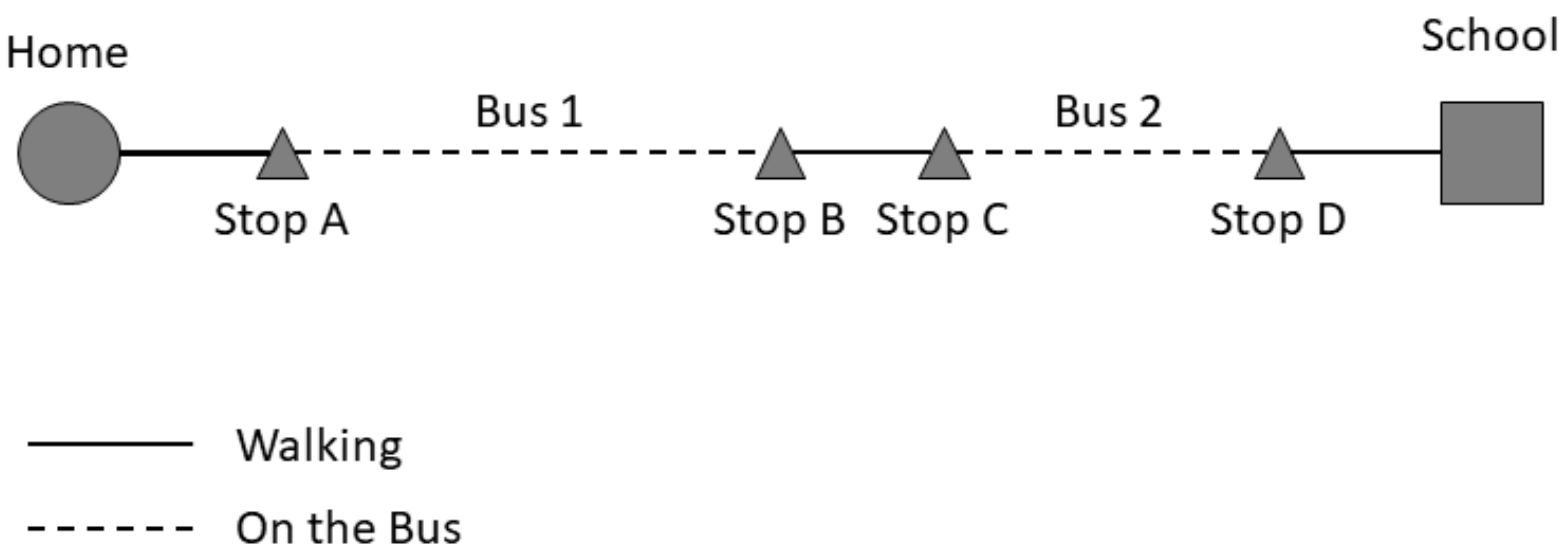

Figure 1: Example trip to school via public transportation.

Figure 3 takes the distribution of crimes at transit stops across the city, smoothed using the kernel density function in ArcGIS, and overlays the estimated number of students who pass through that stop each day on their way to school. Student movement is also highly concentrated in areas that serve as transfer points in the system, particularly the area just north of the harbor, where many of the bus lines converge. This area also has a high density of violent crimes near stops. However, there are other high-volume transit points, especially in the northern corners of the city, which are substantially safer. Overall, the maps show that students experience quite a bit of variability in exposure to violent crime along their routes to school. Students attending the same school or living in the same neighborhood may have very different experiences and levels of stress as they make their way across the city to school.

Figure 4 focuses in on one specific neighborhood in Baltimore. Harlem Park is located in the middle of the high-violent-crime area in central-west Baltimore. The figure shows block by block the violent-crime count for each street segment. Streets with no reported violent crime are drawn in gray, whereas those with reported crimes are drawn in black. Thicker lines indicate a larger number of crimes. There is one school in the neighborhood, located just north of a large park, and a number of bus lines run through the neighborhood. There were 138 violent crimes reported in this neighborhood during the 2014-2015 school year. This places it above the 90th percentile of neighborhoods in terms of reported violent crime. The figure shows that although the neighborhood as a whole is quite violent, the violence is concentrated in a relatively small number of street segments. Depending on exactly where students live or what bus they take, their exposure to violent street segments could be quite different. The patterns shown here are quite typical of other high-crime neighborhoods in the city. Crime in lower-violence neighborhoods is less frequent but is also concentrated in a few city blocks. 


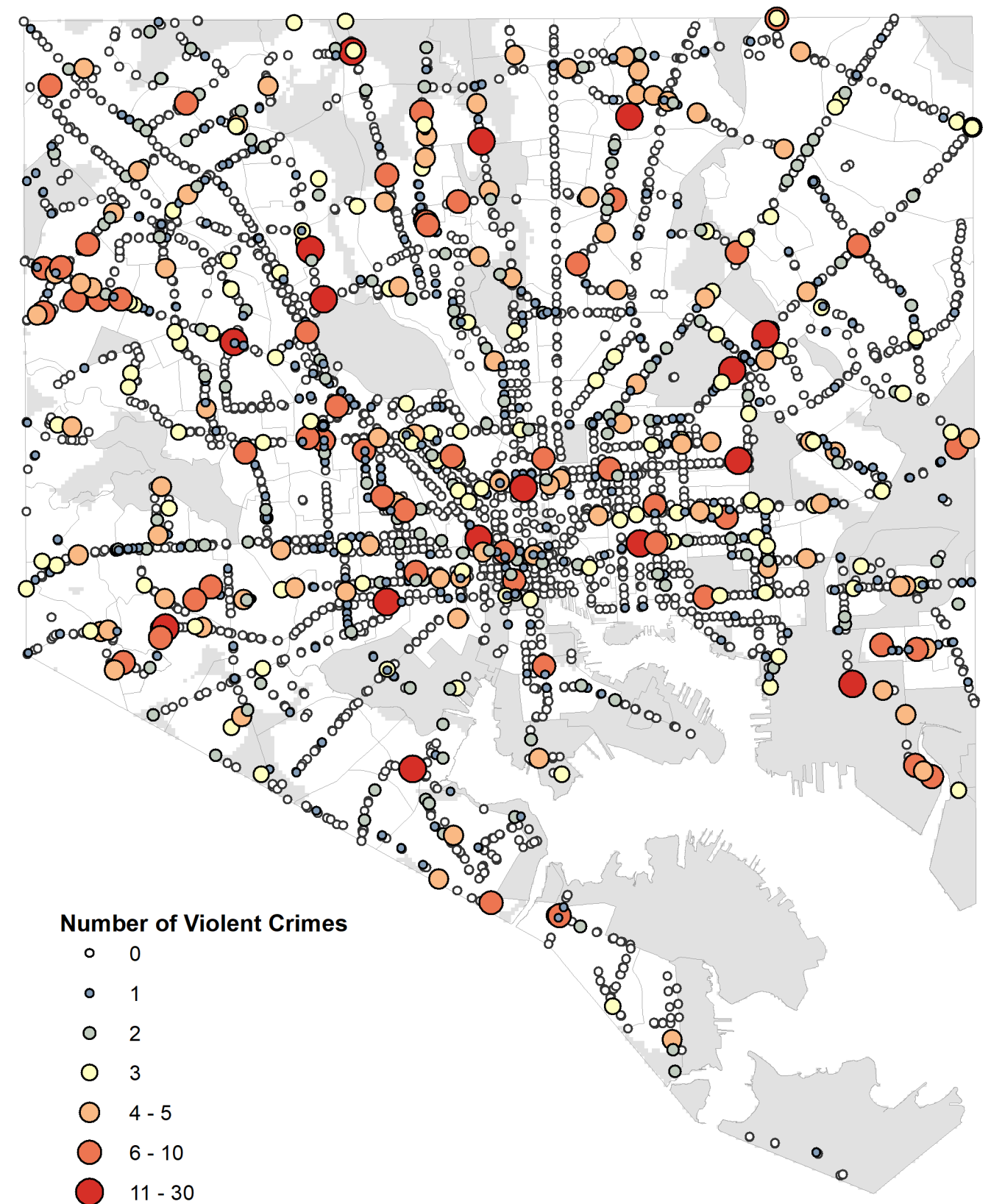

Non-residential areas

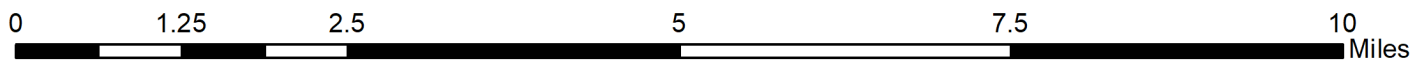

Figure 2: Transit stops by number of violent crimes (2014-2015 academic year). Source: Authors' calculation is based on data from the Baltimore Police Department, the Maryland Transit Administration, and the Baltimore City Public Schools. 


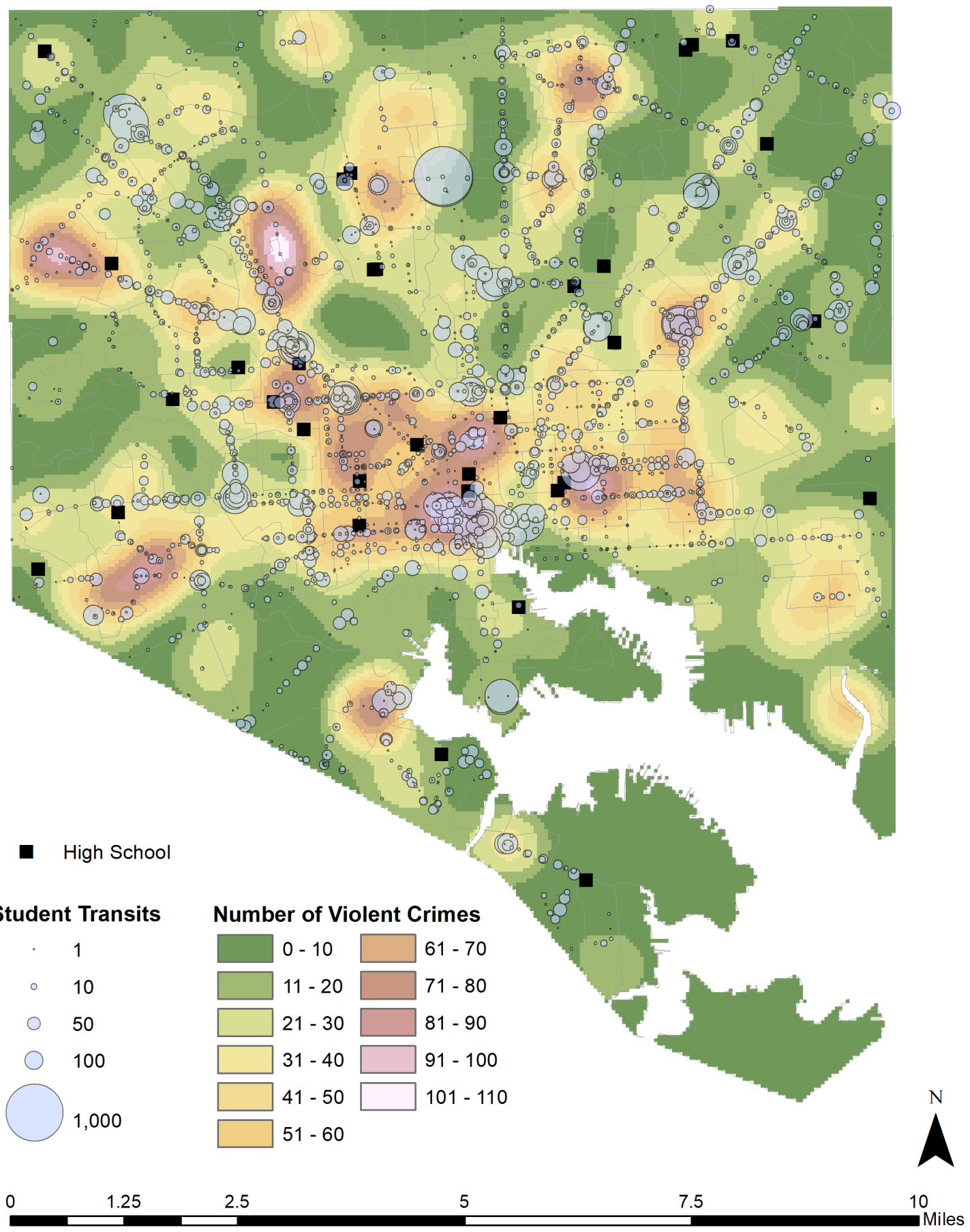

Figure 3: Transit stops by volume of student usage and number of violent crimes (2014-2015 academic year). Source: Authors' calculation is based on data from the Baltimore Police Department, the Maryland Transit Administration, and the Baltimore City Public Schools. 


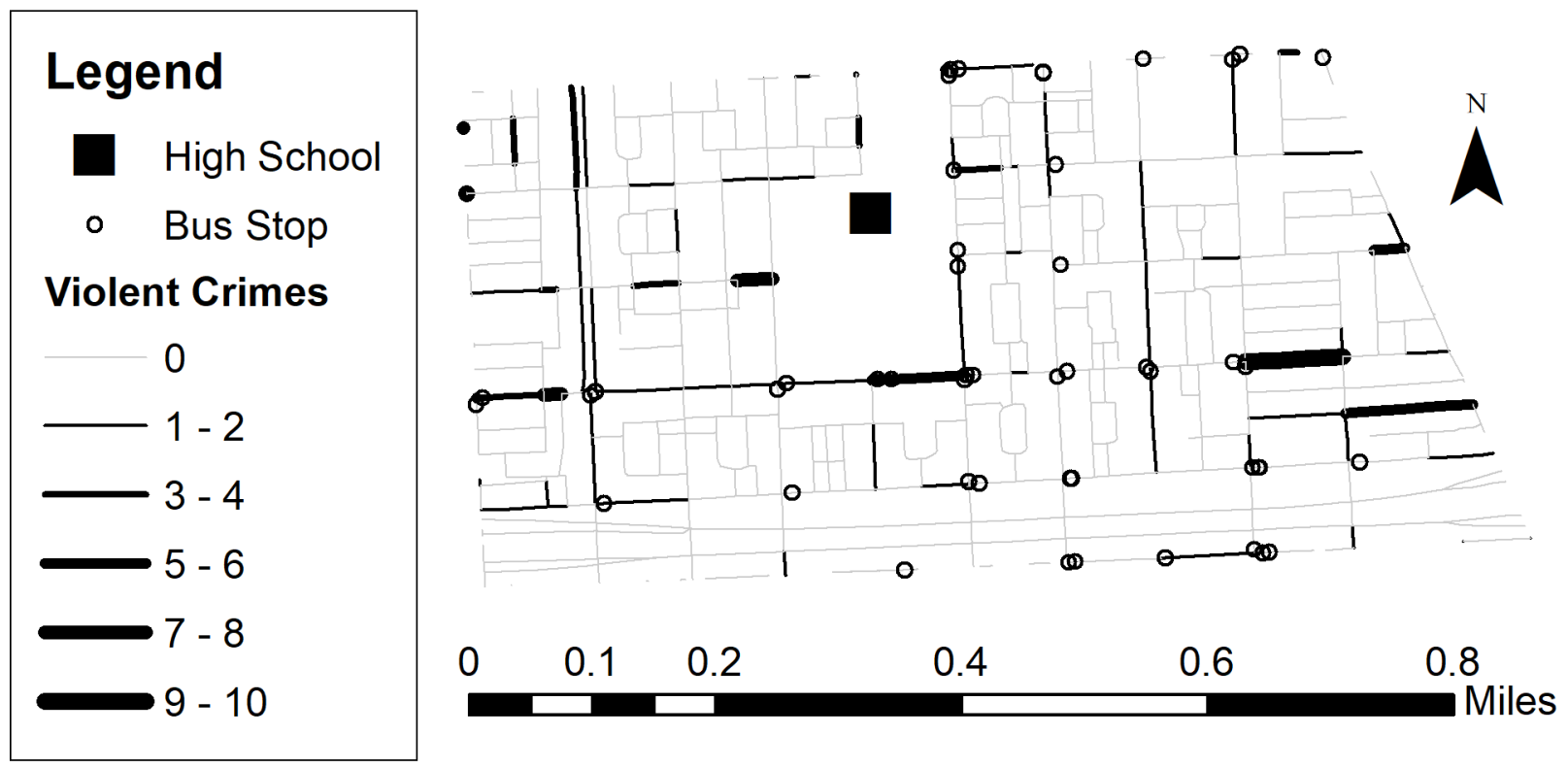

Figure 4: Schools, bus stops, and violent crime by street in Harlem Park, Baltimore (2014-2015 academic year). Source: Authors' calculation is based on data from the Baltimore Police Department, the Maryland Transit Administration, and the Baltimore City Public Schools.

\section{Methods}

Using the spatially linked transit and crime data, we first describe the extent to which students are exposed to dangerous environments on their way to school and how those environments differ from the areas around their schools and homes. We then compare the annual number of absences with exposure to violent crime during different portions of each student's estimated route to school. We adjust the estimates for basic student demographics, the number of absences in the prior year, and other characteristics of their commute, such as length and number of transfers.

Given the skewed distribution of both the absence measures and the violentcrime counts, we transform each of these variables using the inverse hyperbolic sine (IHS) function. This transformation is frequently used when modeling wealth and has the benefit of a similar interpretation as the log transformation but can be used when values include zero (Burbidge, Magee, and Robb 1988). When including the IHS transformations, the errors are very close to normally distributed and homoscedastic with regard to walking exposure to violence. Appendix A in the online supplement provides a histogram of the raw and transformed values as well as a histogram of the errors and a scatter plot of walking violence exposure.

In order to adjust for some of the potential unobserved differences in school engagement and preference, we also adjust for each of the schools that students listed on their high-school-choice applications. By adjusting for the individual schools listed by students, we are able to compare students who expressed a preference for the same set of schools. Other research has shown that these preferences are related not only to academic rigor and extracurricular availability but also geographic 
location and commute time (Bell 2009; Harris and Larsen 2014). Although this will not account for all confounding between students, it likely reduces the bias associated with different school preferences.

The relationship between a commute that exposes students to violent crime and attendance may be confounded by differences between students related to where they reside. For example, even students who express preferences for the same school may experience different neighborhood conditions, such as poverty, social isolation, or geographic inaccessibility, that may be related to both their routes to school and their attendance patterns. In order to adjust for these unobserved differences as well as possible, we include neighborhood fixed effects. These models adjust for any unobserved differences that are constant across students in the same neighborhood, such as neighborhood demographics, transit availability, and distance to job centers or major roads. It also adjusts for differences that lead to the selection of different kinds of families into different neighborhoods, such as the housing stock quality, rental prices, and local school quality.

To assess whether safety concerns are driving differences in attendance, we also estimate the same models using property crimes along students' commute. By definition, these crimes do not involve the same threat to personal wellbeing, and we do not expect that they will have the same relationship with absenteeism. We also test whether the relationship between exposure to violence and attendance varies across different types of students by estimating interaction effects between student characteristics and our main walking violence exposure measure.

Finally, we provide two robustness checks. First, we limit the sample to students with valid eighth-grade standardized-test scores and show that including a measure of prior achievement does not change the estimated relationship between walking violence exposure and attendance. Second, we take advantage of the prior attendance measure as a placebo test. Because this measure of attendance takes place before ninth-grade exposure to violence, we should not expect there to be (and do not find) any relationship between our measure of walking exposure to violence and earlier attendance.

\section{Results}

Table 1 describes the cohort of first-time freshmen used in this analysis as well as the students who are excluded due to grade repetition and school mobility. The analytic sample is equally divided between males and females, but the students are overwhelmingly black and qualify for free and reduced-price meals. Despite only including regular-education high schools, around 18 percent of students qualify for special education services. Only around 2 percent are English-language learners. Ninth graders excluded from the analysis were more likely to be Hispanic and English-language learners.

On average, students in the sample were estimated to take approximately 36 minutes to get to school. Many students were estimated to require a transfer, which results in an average of 1.8 stops. Only around 8 percent of students were estimated to walk to school without taking public transit. Students who were excluded from 
Table 1: Characteristics of students and their commutes.

\begin{tabular}{lcccc}
\hline & \multicolumn{2}{c}{ Analytic Sample } & \multicolumn{2}{c}{ Excluded Students } \\
& Mean & $\begin{array}{c}\text { Standard } \\
\text { Deviation }\end{array}$ & Mean & $\begin{array}{c}\text { Standard } \\
\text { Deviation }\end{array}$ \\
\hline Male & 0.49 & - & 0.47 & - \\
Black & 0.88 & - & 0.82 & - \\
Hispanic & 0.04 & - & 0.11 & - \\
Asian American & 0.01 & - & 0.01 & - \\
Free and Reduced-Price Meals & 0.84 & - & 0.86 & - \\
Special Education & 0.18 & - & 0.19 & - \\
English-Language Learner & 0.02 & - & 0.08 & - \\
Attend Selective High School & 0.27 & - & 0.08 & - \\
Attend Vocational High School & 0.2 & - & 0.11 & - \\
Attend First Choice & 0.5 & - & 0.08 & - \\
Time in Transit & 36.1 & 14.5 & 33.9 & 15.2 \\
Number of Stops & 1.82 & 1.02 & 1.67 & 1.06 \\
Walk Only & 0.08 & 0.27 & 0.11 & 0.31 \\
Days Absent & 19.6 & 26 & 47.2 & 43.8 \\
Absences Last Year & 10.3 & 12.4 & 39.3 & 38.9 \\
Walking Violence Exposure & 26.9 & 21.1 & 28.2 & 20.1 \\
On-the-Bus Violence Exposure & 41 & 40.8 & 37.5 & 42.6 \\
Violent Crimes Near School & 86.9 & 67.7 & 94.3 & 68.8 \\
Violent Crimes Near Home & 95.3 & 82.7 & 99 & 79.4 \\
N & 4,187 & & 2,160 & \\
\hline
\end{tabular}

Source: Authors' calculation is based on data from the Baltimore Police Department, the Maryland Transit Administration, and the Baltimore City Public Schools.

the analysis tended to have slightly shorter commutes and were somewhat more likely to live within walking distance of their schools.

Chronic absenteeism is a serious problem in Baltimore City high schools. On average, students in the analytic sample miss around 20 days of the 179-day school year. This is a substantial increase from the previous year, when the average was only 10 days for the same students, and reflects the dramatic increase in absenteeism between middle and high school (Stein and Grigg [forthcoming]). Absenteeism among the students who were excluded from the analytic sample was substantially higher, with students missing around 47 days per year.

Approximately 27 percent of students in the analytic sample attended a collegepreparatory selective-enrollment school that required a composite score to determine eligibility. An additional 20 percent attended a selective vocational high school (including the arts-focused school). Around half of the sample attended their first-choice school. Those who are excluded from the analytic sample were much less likely to attend either type of selective-enrollment school and attend their first choice.

Violent-crime exposure in all locations is highly variable and quite skewed, with the mean often being equal to the standard deviation. Crime counts in neighborhoods around schools and residences are higher than those along specific commut- 
ing routes because the number of crimes in each location is related to the size of the area in which it is measured. The crime counts for residential and school neighborhoods include all streets in a given area, whereas the commuting crime counts only include crimes along the specific estimated travel routes. On average, the neighborhoods where students go to school appear somewhat safer than those in which they live. The average student went to a school in a neighborhood where 87 violent crimes were reported during the academic year but lived in a neighborhood where 95 violent crimes were reported during the same period. Students pass streets on public transit where there were 41 violent crimes during the school year, on average, and pass streets on foot where there were 27 violent crimes. Considering the substantially shorter distances traveled on foot, this is quite a bit of exposure to violent crime along these specific street blocks and stops.

Table 2 describes the correlation between the two measures of commuting violent-crime exposure, walking violence exposure and on-the-bus violence exposure, and the other variables in the analysis. The absence and crime variables presented in the table are transformed using the IHS function. The correlation between the two travel violent-crime measures is only 0.11 . This suggests that the streets that students pass through on public transit differ substantially from those that they travel on foot. Walking violence exposure has a substantially stronger relationship with attendance than on-the-bus violence exposure.

Figure 5 shows the results of regressions predicting the total number of missed days (see Table B1 in the online supplement for complete models). The first model includes all of the observed covariates discussed previously. Absence in the prior year is highly predictive of current-year absence and soaks up much of the variation in attendance, leaving many of the covariates statistically insignificant. Nevertheless, a 1 percent change in walking violence exposure predicts (on average) a 0.10 percent change in attendance. The estimate is very precise, with a standard error (s.e.) of less than 0.02. In other words, when violent crime doubles (i.e., 100 percent increase), predicted attendance is expected to decrease by approximately 10 percent. At the average level of absence (19.6 days), that translates to an additional 1.9 missed days. This is larger than the predicted association between neighborhood violence and attendance (see Table B2 in the online supplement; $\beta=0.06$ ). On the other hand, exposure to violent crime while riding the bus or train and violent crime around school are not associated with any change in attendance. The coefficients are very small ( -0.005 and 0.004 , respectively) and very imprecise.

The next model (see Figure 5 and Table B2 [model 2] in the online supplement) includes the indicators for the schools that students listed on their choice forms and for the neighborhood fixed effects. Including these adjustments decreases the precision of the estimates and reduces the estimated walking violence exposure coefficient to 0.06 . In other words, when walking violence exposure doubles, we predict an increase in absences of approximately 6 percent. At the average level of absence, this translates to one additional day. In all of these models, exposure while riding public transit remains small and imprecise.

As a specification check, model 2 was rerun using property crime rather than violent crime. Neither outside nor transit exposure to property crime has a substantial or precise relationship with attendance $(\beta=0.001$ [s.e. $=0.002$ ] and $\beta=0.009$ [s.e. 
Table 2: Correlations between location of violence exposure and days absent.

\begin{tabular}{lcccc}
\hline & Days Absent & Walking & On the Bus & School \\
\hline Walking & 0.14 & & & \\
On the Bus & -0.01 & 0.11 & & \\
Around School & 0.14 & 0.04 & -0.06 & \\
In Neighborhood & 0.09 & 0.09 & -0.03 & 0.05 \\
\hline
\end{tabular}

Note: Days absent and all measures of violence exposure have been transformed using the inverse hyperbolic sine function. Source: Authors' calculation is based on data from the Baltimore Police Department, the Maryland Transit Administration, and the Baltimore City Public Schools.

$=0.03]$, respectively; see Appendix Table $\mathrm{C} 1$ in the online supplement for details). This suggests that it is not just crime in general or police presence along a route but threats to personal safety that lead to reductions in attendance.

\section{Interactions}

One might expect the relationship between exposure to violence and attendance to vary for different students. However, we find no evidence that this is the case. The interaction terms with gender, race, free and reduced-price meals, special education, and English-language learners are generally small and very imprecise (see Appendix Table $\mathrm{C} 2$ in the online supplement). Although this may come as a surprise given other work documenting strong race and gender variation in neighborhood effects (Clampet-Ludquist et al. 2011; Sharkey 2010), it is consistent with other research using administrative data to measure violence exposure (Burdick-Will 2013, 2017, 2018).

Another possibility is that students with a stronger attachment to their schools are less vulnerable to the effects of a dangerous commute. We test this idea with an interaction between the indicator that a student is attending his or her first-choice school and the walking violence exposure measure (see Table C2 [column 7] in the online supplement). Although the coefficient for walking violence exposure is larger for students who do not attend their first-choice schools $(\beta=0.09)$, the estimated interaction term is very imprecise $(\beta=0.06$; s.e. $=0.04)$ and suggests that there is not a consistent difference between students who attend their first-choice schools and those who do not.

\section{Robustness Checks}

Although the main models adjust for many observed and unobserved characteristics of students that could be related to both attendance and commute, there is one measure that we have no accounted for: achievement. Perhaps students who are doing better in school are different, above and beyond their prior attendance record and the type of school they attend, in ways that bias our results. Unfortunately, although we have a measure of prior achievement available (eighth-grade standardized-test scores), this measure is missing for 4.7 percent of the analytic 


\section{Violence Exposure Coefficients by Location}

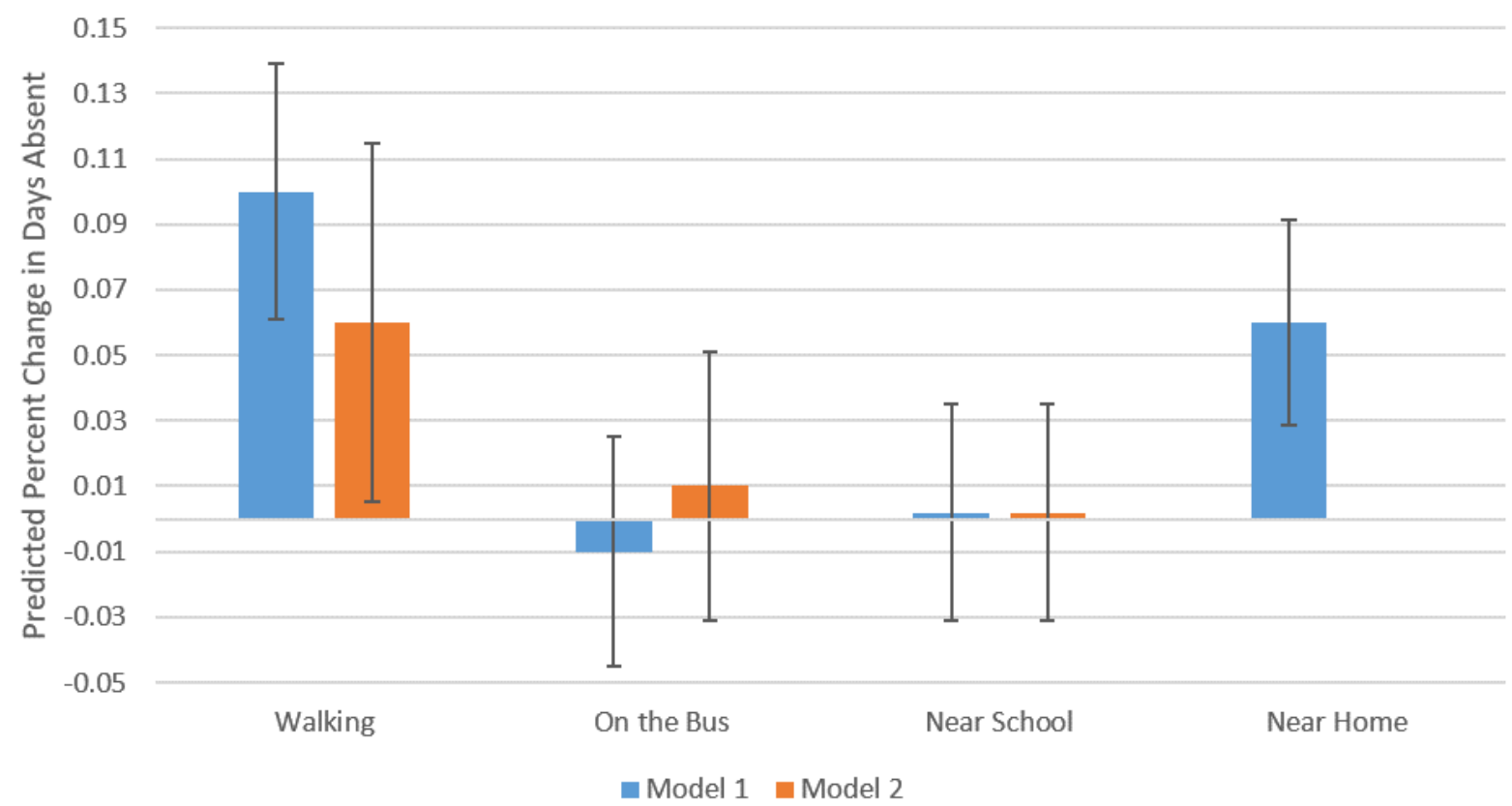

Figure 5: Predicted percentage change in days absent by location of exposure to violent crime. There were 4,187 observations: model $1 R^{2} 0.33$, model 2 within $R^{2} 0.33$, between $R^{2} 0.49$, overall $R^{2} 0.36$. All measures of days absent and crime exposure have been transformed using the inverse hyperbolic sine function and can be interpreted as a percentage change. All models include last year's days absent, total travel time, number of stops, an indicator for walking only, gender, race, special programs eligibility, and whether students attend selective or vocational schools. Model 2 includes school-choice indicators and neighborhood fixed effects. See Appendix B in the online supplement for complete models. Source: Authors' calculation is based on data from the Baltimore Police Department, the Maryland Transit Administration, and the Baltimore City Public Schools. 
hand, if there is no relationship, it suggests that the timing of exposure matters and, therefore, provides more evidence that the results are not driven solely by selection bias. Therefore, we run the same models with all of the same predictors as in model 2 but with last year's absenteeism rate as the outcome. In this model, the coefficients for both walking violence exposure and transit violence exposure are small and very imprecise $(\beta=0.03$ [s.e. $=0.03$ ] and $\beta=0.03$ [s.e. $=0.02$ ], respectively; see Appendix Table $C 4$ in the online supplement for details).

\section{Discussion}

The social environments that students are exposed to while commuting on public transportation appear to have a strong relationship with their school attendance. Specifically, when students must walk or wait in areas with higher crime rates, they are more likely to be absent from school. This relationship remains even after adjusting for school preferences and neighborhood fixed effects. Based on our final model, when walking violence exposure doubles, we predict an approximately 6 percent increase in absenteeism, which translates to an additional day of absence for the average attender. Travel through unsafe areas while within the confines of the bus or train does not have the same relationship with attendance. In other words, when students are required to walk to and from transit stops and make transfers on public transportation, they are likely more vulnerable through increased exposure to violent areas than they would be commuting via private vehicle or if they were picked up by a designated school bus close to home that takes them directly to school.

Although at first it may not seem like a single day is particularly large, it is important to note a few things. Because the measure of violent crime is based only on specific street segments, the overall counts are relatively low. Doubling in this context is not a difficult scenario to imagine. For streets that tend to only have relatively low levels of violent crime, a handful of additional incidents is not unheard of and could dramatically change the perception of the area. Second, given the cumulative nature of schooling, even a single day's absence can mean a large loss of learning over the course of a year. When students miss even a little bit of the information needed to complete an assignment or background information, it can make future learning much more difficult. Third, when aggregated to a whole classroom, multiple students missing class on different days can make it hard for teachers to move through the curricula. Time spent on helping students catch up could otherwise have been spent on presenting new material.

It must also be noted that our findings may underestimate the true relationship between exposure to violence during commuting and attendance. First, for the purpose of simplicity and to avoid confounding mobility, grade retention, and attendance, the analytic sample used here was limited to first-time freshmen who remained in the same school for the whole year. As seen in Table 1, these are not the students with the highest absenteeism rates. In other words, in general, these are the students who are generally doing a good job of getting themselves to school every day. Students who show disengagement from school in other ways, such as 
grade repetition and mobility, are potentially more sensitive to influences that limit attendance.

Second, the measures used here are limited in their precision and timing. Violentcrime exposure is measured along the students' estimated public transportation routes to school, not their actual behavior. Students who do not take their estimated routes are therefore combined with those who do, and this likely weakens the measure of actual exposure. However, one way to avoid danger may be to take an inefficient route to school, and a longer or more difficult travel time can in turn lead students to miss school more often (Stein and Grigg [forthcoming]). The timing of exposure and attendance is also a potential limitation. This study compares students over the whole school year, and it is therefore impossible to test whether absenteeism increases in response to a specific event. This study is also subject to concerns about unobserved bias that could be influencing the relationship. Although the inclusion of covariates, such as last year's attendance, exposure to violence in other settings, and school preferences, limits that concern, it can never be entirely eliminated. Therefore, future research should examine students' actual routes to school and how the timing of exposure may lead to attendance problems on some specific days but not others.

Nevertheless, there are a few points that suggest that the results are not merely driven by the selection of low-attendance students into commutes that expose them to more violence. First, the results remain even after adjusting for students' stated school preferences and neighborhood fixed effects. This means that the models compare two students who live in the same neighborhood and wanted to go the same set of schools but were assigned different schools and therefore commutes by the school-choice system. Second, exposure to violent crime while on the actual bus or train is not related to absenteeism. The lack of a relationship between on-thebus violence exposure and attendance suggests that the vulnerability associated with being outside is driving the effects rather than other more general aspects of the commute. Third, exposure to violence during the commute is not related to attendance in the previous year, suggesting that stable differences between kids are not driving the results. Finally, the lack of effect of property crimes in the same locations suggests that general crime or police presence is not the issue but that the risk of physical victimization associated with violent crime is.

\section{Conclusion}

Accounting for the commute to school is increasingly important in the context of increasing school choice and open enrollment policies that require many students to travel long distances to get to school (Shedd 2015; Stein et al. 2017). Urban school districts often rely on public transportation systems to move substantial proportions of youth to schools all across the city. Although the monetary costs of public transit may be subsidized, the experience of relying on mass transit is often inferior to driving. Because transit rarely brings students door to door, walking and waiting are inherently part of the experience, and even if the travel times are comparable, unreliable bus schedules require building in extra wait times to ensure on-time arrival (Koslowsky et al. 1995). This means that students who rely on 
public transportation to commute to school may spend substantial amounts of time during their commute outside the relative safety of the transit vehicle, walking to or waiting at transit stops, thereby increasing their potential exposure to areas of violent crime.

The inconveniences of public transportation as a method to get students to school are not equally distributed. First, racially and economically disadvantaged students are more likely to live in urban areas (Orfield and Lee 2005), and urban areas are more likely to have mass transit systems that students use to get to school. They are also areas where school districts do not provide traditional yellow school buses, and parents are less likely to be able to afford their own private transportation to school. For example, Baltimore City provides middle- and high-school students with public transit passes, but nearby suburban Baltimore County provides a charter bus service (Baltimore City Public Schools 2018; Baltimore County Public Schools 2016). Second, in cities like Baltimore, selective-enrollment, magnet, and charter schools are often located outside of highly disadvantaged neighborhoods, necessitating longer commutes for the disadvantaged students who are most likely to be taking public transportation (Burdick-Will, Keels, and Shuble 2013; Lubienski, Gulosino, and Weitzel 2009; Stein et al. 2017).

The relationship between exposure to violence during the commute to school and absenteeism documented in this study, therefore, provides important insights into the possible mechanisms linking neighborhood violence to low achievement and high-school dropout. Not only are students potentially stressed and traumatized by the chronic violence in their communities, they may also miss school at higher rates as a result of avoiding direct physical danger on the streets while commuting to school. To date, when the literature on neighborhood effects includes discussions of attendance, it is usually in the context of available role models or an inability to see the point of going to school (Harding 2010; Wilson 1987). However, these results suggest that physical impedances and the potential for strategic absence need to be considered in any discussion of the relationship between the neighborhood social environment and the importance of attendance and physical presence at school. Every day these students must weigh the incremental benefit of one more day at school against the possibility of real physical injury or death on the way to school. Avoiding danger on the way to school may mean taking a longer-than-necessary route to school, waiting for an unreliable ride to a safer bus stop, or avoiding the trip to school altogether.

\section{References}

Allensworth, Elaine M., and John Q. Easton. 2007. What Matters for Staying On-Track and Graduating in Chicago Public High Schools: A Close Look at Course Grades, Failures, and Attendance in the Freshman Year. Research Report. Chicago, IL: University of Chicago Consortium on Chicago School Research.

Allensworth, Elaine M., Julia A. Gwynne, Paul Moore, and Marisa de la Torre. 2014. Looking Forward to High School and College: Middle Grade Indicators of Readiness in Chicago Public Schools. Chicago, IL: University of Chicago Consortium on Chicago School Research. 
Amponsah-Tawiah, Kwesi, Francis Annor, and Beckham Godfred Arthur. 2016. "Linking Commuting Stress to Job Satisfaction and Turnover Intention: The Mediating Role of Burnout." Journal of Workplace Behavioral Health 31:104-23. https://doi .org/10 . 1080/ 15555240.2016.1159518.

Balfanz, Robert, and Vaughan Byrnes. 2012. The Importance of Being in School: A Report on Absenteeism in the Nation's Public Schools. Baltimore, MD: Center for Social Organization of Schools and Johns Hopkins University.

Balfanz, Robert, Liza Herzog, and Douglas J. Mac Iver. 2007. “Preventing Student Disengagement and Keeping Students on the Graduation Path in Urban Middle-Grades Schools: Early Identification and Effective Interventions." Educational Psychologist 42:22335. https://doi.org/10.1080/00461520701621079.

Baltimore City Public Schools. 2018. "Transportation: MTA and One Card." Baltimore, MD: Baltimore City Public Schools. Retrieved May 15, 2018 (http://www . baltimorecityschools.org/Page/30706).

Baltimore County Public Schools. 2016. “Parents' and Students' Guide to Transportation." Retrieved May 15, 2018 (http://businessservices.bcps.org/UserFiles/ Servers/Server_9047649/File/Business $\backslash \% 20$ Services/Transportation/ Parents-Students-Guide.pdf).

Baltimore Police Department. 2017. "BPD Part 1 Victim Based Crime data." Retrieved August 30, 2017 (https://data.baltimorecity.gov/Public-Safety/ BPD-Part-1-Victim-Based-Crime-Data/wsfq-mvij).

Bell, Courtney. 2009. “Geography in Parental Choice.” American Journal of Education 115:493521. https://doi.org/10.1086/599779.

Bourgois, Philippe. 1995. In Search of Respect: Selling Crack in El Barrio. Cambridge, UK: Cambridge University Press.

Braga, Anthony A., Andrew V. Papachristos, and David M. Hureau. 2010. "The Concentration and Stability of Gun Violence at Micro Places in Boston, 1980-2008." Journal of Quantitative Criminology 26:33-53. https : //doi .org/10.1007/s10940-009-9082-x.

Browning, Christopher R., Catherine A. Calder, Jodi L. Ford, Bethany Boettner, Anna L. Smith, and Dana Haynie. 2017. “Understanding Racial Differences in Exposure to Violent Areas: Integrating Survey, Smartphone, and Administrative Data Resources." The Annals of the American Academy of Political and Social Science 669:41-62. https://doi.org/10. $1177 / 0002716216678167$.

Burbidge, John B., Lonnie Magee, and A. Leslie Robb. 1988. “Alternative Transformations to Handle Extreme Values of the Dependent Variable." Journal of the American Statistical Association 83:123-7. https://doi.org/10.1080/01621459.1988.10478575.

Burdick-Will, Julia. 2013. "School Violent Crime and Academic Achievement in Chicago." Sociology of Education 86:343-61. https://doi .org/10.1177/0038040713494225.

Burdick-Will, Julia. 2016. "Neighborhood Violent Crime and Academic Growth in Chicago: Lasting Effects of Early Exposure." Social Forces 95:133-57. https://doi .org/10.1093/ sf/sow041.

Burdick-Will, Julia. 2017. "Neighbors, but Not Classmates: Neighborhood Disadvantage, Local Violent Crime, and the Heterogeneity of Educational Experiences in Chicago." American Journal of Education 124:27-65. https://doi .org/10.1086/693958.

Burdick-Will, Julia. 2018. "Neighborhood Violence, Peer-Effects, and Academic Achievement in Chicago." Sociology of Education 91:205-23. https://doi.org/10.1177/ 0038040718779063. 
Burdick-Will, Julia, Micere Keels, and Todd Shuble. 2013. “Closing and Opening Schools: The Association between Neighborhood Characteristics and the Location of New Educational Opportunities in a Large Urban District." Journal of Urban Affairs 35:59-80. https: //doi.org/10.1111/juaf.12004.

Clampet-Lundquist, Susan, Kathryn Edin, Jeffrey R. Kling, and Greg J. Duncan. 2011. “Moving Teenagers Out of High-Risk Neighborhoods: How Girls Fare Better than Boys." American Journal of Sociology 116:1154-89. https: //doi .org/10.1086/657352.

Cohen, Lawrence E., and Marcus Felson. 1979. "Social Change and Crime Rate Trends: A Routine Activity Approach." American Sociological Review 44:588-608. https : //doi .org/ $10.2307 / 2094589$.

Condliffe, Barbara F., Melody L. Boyd, and Stefanie DeLuca. 2015. "Stuck in School: How Social Context Shapes School Choice for Inner-City Students." Teachers College Record 117:1-36.

Einhorn, Erin. 2016. "Six Hours, Eight Buses: The Extreme Sacrifice Detroit Parents Make to Access Better Schools." Chalkbeat, April 8. Retrieved April 26, 2018 (https://detroit.chalkbeat.org/posts/detroit/2016/04/08/ six-hours-eight-buses-the-extreme-sacrifice-detroit-parents-make-to- $\backslash$ access-better-schools/).

Furstenberg, Frank F., Thomas D. Cook, Jacquelynne Eccles, Glen H. Elder, Jr., and Arnold Sameroff. 1999. Managing to Make It: Urban Families and Adolescent Success. Chicago, IL: University of Chicago Press.

Gottfried, Michael A. 2010. “Evaluating the Relationship Between Student Attendance and Achievement in Urban Elementary and Middle Schools: An Instrumental Variables Approach." American Educational Research Journal 47:434-65. https : //doi .org/10.3102/ 0002831209350494.

Gottfried, Michael A. 2013. “Can Neighbor Attributes Predict School Absences?” Urban Education 49:216-50. https://doi.org/10.1177/0042085913475634.

Grady, Sarah, and Stacey Bielick. 2010. Trends in the Use of School Choice: 1993 to 2007. Washington, DC: National Center for Education Statistics and U.S. Department of Education.

Harding, David. J. 2009. “Collateral Consequences of Violence in Disadvantaged Neighborhoods." Social Forces 88:757-84. https://doi .org/10.1353/sof .0.0281.

Harding, David J. 2010. Living the Drama: Community, Conflict, and Culture among Inner-City Boys. Chicago, IL: University of Chicago Press. https://doi.org/10.7208/chicago/ 9780226316666.001 .0001$.

Harris, Douglas N., and Matthew Larsen. 2014. What Schools Do Families Want (and Why)? School Demand and Information before and after the New Orleans post-Katrina School Reforms. New Orleans, LA: Education Research Alliance for New Orleans.

Jencks, Christopher, and Susan E. Mayer. 1990. “The Social Consequences of Growing up in a Poor Neighborhood." Pp. 111-86 in Inner-City Poverty in the United States, edited by L. E. Lynn, Jr. and M. G. H. McGeary. Washington, DC: National Academies Press.

Klinenberg, Eric. 2002. Heat Wave: A Social Autopsy of Disaster in Chicago. Chicago, IL: University of Chicago Press. https://doi .org/10.7208/chicago/9780226026718.001. 0001.

Kluger, Avraham N., and Mordechai Reich. 1998. "Commute Variability and Strain." Journal of Organizational Behavior 19:147-65. https: //doi .org/10.1002/(SICI) 1099-1379(199803) 19:2<147: :AID- JOB830>3.0. CO;2-Y. 
Koslowsky, Meni, Avraham N. Kluger, and Mordechai Reich. 1995. Commuting Stress: Causes, Effects and Methods of Coping. New York, NY: Plenum Press. https://doi .org/10 . 1007/ 978-1-4757-9765-7.

Kozol, Jonathan. 1991. Savage Inequalities: Children in America's Schools. New York, NY: Broadway Books.

Lubienski, Christopher, Charisse Gulosino, and Peter Weitzel. 2009. "School Choice and Competitive Incentives: Mapping the Distribution of Educational Opportunities across Local Education Markets." American Journal of Education 115:601-47. https : //doi . org/ $10.1086 / 599778$.

Maryland Transit Administration. 2017. “Developer Resources: GTFS Data." Retrieved August 30, 2017 (https ://mta.maryland.gov/content/developer-resources).

Mac Iver, Martha Abele, and Douglas J. Mac Iver. 2010. Keeping on Track in Ninth Grade and Beyond: Baltimore's Ninth Graders in 2007-08. Baltimore, MD: Baltimore Education Research Consortium.

McKone, Jonna. 2015. "No Yellow Buses Here: One Student's MTA Commute." WYPR, August 24. Retrieved April 26, 2018 (http://wypr.org/post/ no-yellow-buses-here-one-students-mta-commute-0).

Morang, Melinda. 2016. "Map Your Transit Data like Never before." ArcGIS Blog, May 27. Retrieved April 26, 2018 (https://blogs.esri.com/esri/arcgis/2016/05/27/ map-and-understand-your-public-transit/).

Orfield, Gary, and Chungmei Lee. 2005. Why Segregation Matters: Poverty and Educational Inequality. Cambridge, MA: The Civil Rights Project at Harvard University.

Pattillo, Mary. 2008. Black on the Block: The Politics of Race and Class in the City. Chicago, IL: University of Chicago Press.

Ready, Douglas D. 2010. "Socioeconomic Disadvantage, School Attendance, and Early Cognitive Development: The Differential Effects of School Exposure." Sociology of Education 83:271-86. https://doi.org/10.1177/0038040710383520.

Rosenblatt, Peter, and Stefanie DeLuca. 2012. “'We Don't Live Outside, We Live in Here': Neighborhood and Residential Mobility Decisions among Low-Income Families." City and Community 11:254-84. https://doi .org/10.1111/j.1540-6040.2012.01413.x.

Sampson, Robert J., Patrick Sharkey, and Stephen W. Raudenbush. 2008. “Durable Effects of Concentrated Disadvantage on Verbal Ability among African-American Children." Proceedings of the National Academy of Sciences 105:845-52. https://doi . org/10.1073/pnas . 0710189104.

Sánchez-Jankowski, Martin. 2008. Cracks in the Pavement: Social Change and Resilience in Poor Neighborhoods. Berkeley, CA: University of California Press.

Schwartz, Amy Ellen, Agustina Laurito, Johanna Lacoe, Patrick Sharkey, and Ingrid Gould Ellen. 2016. The Academic Effects of Chronic Exposure to Neighborhood Violence (No. 195). Syracuse, NY: Center for Policy Research and The Maxwell School of Syracuse University.

Sharkey, Patrick. 2006. "Navigating Dangerous Streets: The Sources and Consequences of Street Efficacy." American Sociological Review 71:826-46. https://doi .org/10.1177/ 000312240607100506.

Sharkey, Patrick. 2010. “The Acute Effect of Local Homicides on Children's Cognitive Performance." Proceedings of the National Academy of Sciences 107:11733-8. https ://doi. org/10.1073/pnas. 1000690107..

Sharkey, Patrick T., Nicole Tirado-Strayer, Andrew V. Papachristos, and C. Cybele Raver. 2012. “The Effect of Local Violence on Children's Attention and Impulse Control." American Journal of Public Health 102:2287-93. https : //doi .org/10 . 2105/AJPH . 2012 . 300789. 
Shedd, Carla. 2015. Unequal City: Race, Schools, and Perceptions of Injustice. New York, NY: Russell Sage Foundation.

Shonkoff, Jack P., Andrew S. Garner, Benjamin S. Siegel, Mary I. Dobbins, Marian F. Earls, Laura McGuinn, John Pascoe, and David L. Wood. 2012. "The Lifelong Effects of Early Childhood Adversity and Toxic Stress." Pediatrics 129:e232-46. https://doi.org/10. 1542/peds. 2011-2663.

Small, Mario L. 2004. Villa Victoria: The Transformation of Social Capital in a Boston Barrio. Chicago, IL: University of Chicago Press. https://doi.org/10.7208/chicago/ 9780226762937.001 .0001$.

Sørenson, Aage, and Maureen Hallinan. 1977. "A Reconceptualization of School Effects." Sociology of Education 50:273-89. https : //doi .org/10.2307/2112500.

St. Jean, Peter K. 2008. Pockets of Crime: Broken Windows, Collective Efficacy, and the Criminal Point of View. Chicago, IL: University of Chicago Press.

Stein, Marc L., and Jeffrey Grigg. Forthcoming. "Missing Bus, Missing School: Establishing the Relationship between Public Transit Use and Student Absenteeism." American Educational Research Journal.

Stein, Marc L., Jeffrey Grigg, Curt Cronister, Celeste Chavis, and Faith Connolly. 2017. Getting to High School in Baltimore: Student Commuting and Public Transportation. Baltimore, MD: Baltimore Education Research Consortium.

Stutzer, Alois, and Bruno S. Frey. 2008. "Stress that Doesn't Pay: The Commuting Paradox." The Scandinavian Journal of Economics 110:339-66. https://doi .org/10.1111/j. 1467-9442.2008.00542.x.

Urban Institute. 2017. "Student Transportation and Educational Access: How Students Get to School in Denver, Detroit, New Orleans, New York City, and Washington, DC." Retrieved March 24, 2017 (https://doi.org/10.1023/A:1022516221808https://www.urban. $\mathrm{org} / \mathrm{research} / \mathrm{publication/student-transportation-and-educational-access).}$

Venkatesh, Sudhir A. 2000. American Project: The Rise and Fall of a Modern Ghetto. Cambridge, MA: Harvard University Press.

Vincent, Jeffrey, Carrie Makarewicz, Ruth Miller, Julia Ehrman, and Deborah McKoy. 2014. Beyond the Yellow Bus: Promising Practices for Maximizing Access to Opportunity through Innovations in Student Transportation. Berkeley, CA: Center for Cities and Schools.

Wacquant, Loïc. 2008. Urban Outcasts: A Comparative Sociology of Advanced Marginality. Cambridge, UK: Polity.

Wener, Richard E., Gary W. Evans, Donald Phillips, and Natasha Nadler. 2003. "Running for the 7:45: The Effects of Public Transit Improvements on Commuter Stress." Transportation 30:203-20. https://doi .org/10.1023/A : 1022516221808.

Wilson, William J. 1987. The Truly Disadvantaged: The Inner City, the Underclass, and Public Policy. Chicago, IL: University of Chicago Press.

Wodtke, Geoffrey T., David J. Harding, and Felix Elwert. 2011. “Neighborhood Effects in Temporal Perspective the Impact of Long-Term Exposure to Concentrated Disadvantage on High School Graduation." American Sociological Review 76:713-36. https : //doi .org/ $10.1177 / 0003122411420816$. 
Acknowledgments: This research was made possible by a grant from the Spencer Foundation and indirect support from the Baltimore Education Research Consortium and the Hopkins Population Center. Curt Cronister provided invaluable technical support. We are grateful for the feedback from and assistance of the Baltimore City Public Schools. All errors and opinions are our own.

Julia Burdick-Will: Department of Sociology and School of Education, Johns Hopkins University. E-mail: jburdickwill@jhu.edu.

Marc L. Stein: School of Education, Johns Hopkins University. E-mail: m.stein@jhu.edu. Jeffrey Grigg: School of Education, Johns Hopkins University. E-mail: jgrigg1@jhu.edu. 